\title{
Evidence-Based Guidelines for the Pharmacological Management of Acute Methamphetamine-Related Disorders and Toxicity
}

\author{
Authors \\ Norbert Wodarz ${ }^{1 *}$, Anne Krampe-Scheidler ${ }^{2 *}$, Michael Christ ${ }^{3}$, \\ Heribert Fleischmann ${ }^{4}$, Winfried Looser ${ }^{5}$, Katharina Schoett ${ }^{6}$, Frank \\ Vilsmeier ${ }^{7}$, Lydia Bothe ${ }^{2}$, Corinna Schaefer ${ }^{2}$, Euphrosyne Gouzoulis- \\ Mayfrank $^{8}$ \\ Affiliations \\ 1 Center of Addiction Medicine, Department of Psychiatry and \\ Psychotherapy at the Bezirksklinikum, University of Regensburg, \\ Regensburg \\ 2 German Agency for Quality in Medicine (ÄZQ), Berlin \\ 3 Department of Emergency Medicine and Internal Intensive Care, \\ Klinikum Nürnberg Nord, Nürnberg \\ 4 District Hospital Wöllershof, Neustadt/WN \\ 5 LVR Clinic Düren, Düren \\ 6 Deptartment of Addiction Medicine, Ökumen. Heinrichklinikum, \\ Mühlhausen \\ 7 Psychiatric Hospital, Rickling \\ 8 Clinic Cologne, Köln
}

Key words

(Crystal) methamphetamine, intoxication, withdrawal, methamphetamine-induced psychosis, treatment guidelines

received $\quad 09.05 .2016$

revised 29.11.2016

accepted 05.12 .2016

Bibliografie

DOI http://dx.doi.org/10.1055/s-0042-123752

Published online: 15.3.2017

Pharmacopsychiatry 2017; 50: 87-95

(c) Georg Thieme Verlag KG Stuttgart · New York

ISSN 0176-3679
Correspondence

Prof. Dr. Norbert Wodarz

Dept. of Psychiatry and Psychotherapy at the Bezirksklinikum

University of Regensburg

Universitaetsstr. 84

93042, Regensburg

Germany

\begin{abstract}
Consumption of methamphetamine ("crystal") has spread dramatically over several European countries. The management of methamphetamine-induced acute disorders has become a growing challenge to the health system. Pharmacological treatment strategies for methamphetamine-induced intoxication syndromes, acute withdrawal symptoms, and methamphetamine-induced psychosis are particularly important. The development of interdisciplinary and evidence- and consensusbased (S3) German Guidelines was based on a systematic literature and guideline search on therapeutic interventions in methamphetaminerelated disorders (April, June 2015). Consideration was given to 9 guidelines and 103 publications. Recommendations on pharmacological treatment strategies were drawn up using the nominal group technique. Overall, only limited evidence is available. Benzodiazepines are first-line medication for methamphetamine-induced intoxication syndromes, particularly when they present with acute agitation and aggressive behavior. There is no evidence-based medication for the treatment of methamphetamine-related withdrawal symptoms and cravings. When treating methamphetamine-induced psychosis, second-generation antipsychotics should be favored, given their more favorable side-effect profile. The indication for continuation of antipsychotic medication must be reviewed regularly. In most cases, the antipsychotic should be tapered off within 6 months.
\end{abstract}

\section{Introduction}

In several European countries, doctors and staff in hospitals, practices, and addiction treatment centers are faced with rapidly increasing numbers of subjects who suffer from acute complications of the use of methamphetamine (crystal). Although epidemiological data on methamphetamine use are still limited, the rate of (meth) amphetamine-induced mortality is currently increasing in Germany. Mortality is mostly due to cardiovascular complications or HIV infection.

Methamphetamine acts as a potent agonist at the trace amineassociated receptor 1 (TAAR1). Among other effects, this results in the internalization or the reverse function of plasma membrane

1,4-7,10 for the Working Group of the S3 Guidelines "Methamphetamine-related Disorders": http://www.aezq.de/aezq/crystal-meth

* These authors contributed equally to this work. and the vesicular monoamine transporters via protein kinase $\mathrm{A} / \mathrm{C}$ phosphorylation [1]. According to in-vitro studies, methamphetamine is twice as potent at releasing noradrenaline (NA) compared to dopamine and 60 -fold as potent at releasing NA compared to serotonin [2]. Due to its high lipophilicity, methamphetamine is absorbed thoroughly following inhalation and oral or intranasal administration and it moves through the blood-brain barrier faster than other stimulants. The half-life of methamphetamine is quite variable, ranging from 5 to $30 \mathrm{~h}$. It is excreted by the kidneys, usually around $30-50 \%$ as methamphetamine and $10-25 \%$ as amphetamine [3].

This paper aims to present the available evidence and derive consensus-based expert recommendations on the pharmacological treatment strategies for methamphetamine-induced intoxication, acute methamphetamine withdrawal, and methamphetamine-induced psychosis. 


\section{Methods}

We performed a systematic literature search on therapeutic interventions for methamphetamine-related disorders in June 2015 using the following databases: Cochrane Library, Medline via PubMed, PSYINDEX via DIMDI, and OVID database "PsycINFO2." A manual search was made in addition. The search strategy was very sensitive in order to include all treatment-relevant studies ( $\triangleright$ Table 1). We included all studies (irrespective of the type of study) and systematic reviews on therapeutic interventions in humans with methamphetamine-related disorders published since 2000. In addition, we searched systematically the Library of the Guidelines International Network (GIN) and the AWMF (Association of Scientific Medical Societies in Germany) database for relevant guidelines ( Table 2).

Papers were included if they reported a suitable topic (methamphetamine-related); the type of publication was a systematic review, randomized clinical trial (RCT), or case series; the language was German or English; and the publication period was 2000-2015. Suitable topics were harm reduction (number of papers included

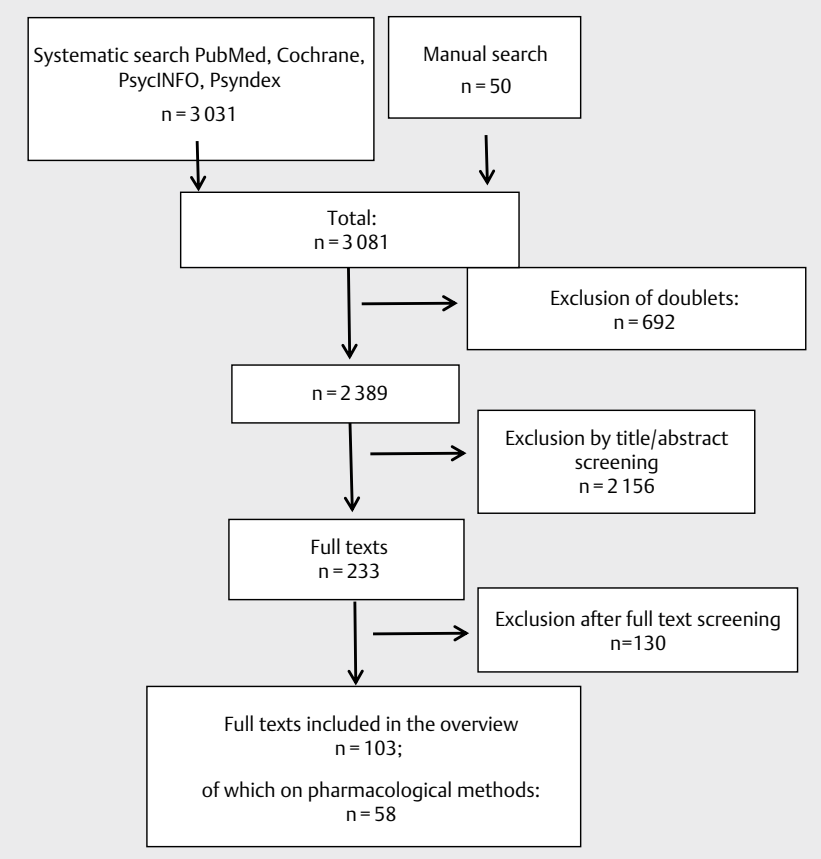

Fig. 1 Flow Chart: Systematic search. $n=4)$, pharmacotherapy $(n=58)$, psychotherapy $(n=26)$, pharmaco- and psychotherapy $(n=3)$, and other therapies (e. g., acupuncture, sport) $(n=12)$.

Papers were excluded if they reported no suitable topic or study type. Excluded were preclinical studies, epidemiological studies (number of papers excluded $n=107$ ), number of patients $<10$ $(n=9)$, predictive factors $(n=39)$, studies on dental problems $(n=9)$, publication withdrawn $(n=2)$ or not available $(n=1)$, editorials, abstracts, etc. $(n=114)$, and non-German or English language $(n=3)$.

All included studies were extracted to evidence tables (piloted forms). We used the tool of the Oxford Centre for Evidence-Based Medicine 2011 (OCEBM) in order to assess methodological quality and grade the evidence [4]. Furthermore, we used the Cochrane Risk of Bias Tool to record and present the methodological limitations of RCTs. We did not contact study authors for questions. Guidelines were assessed using the DELBI instrument. The AMSTAR score was utilized for systematic reviews. In case of uncertainty regarding the assessment, assignment of levels of evidence, or inclusion/exclusion, a second reviewer independently assessed the trials, reviews, or guidelines in question. Discrepancies were discussed and resolved by consensus between the 2 reviewers ( $>$ Fig. 1).

A systematic search for guidelines on methamphetamine or amphetamine-type stimulants was performed in April 2015 ( $\triangleright$ Table 3). The search strategy and terminology were geared to the different search functions of each database and were modified correspondingly. We included documents in German or English. There were no restrictions regarding patient groups ( $\triangleright$ Table 4 ).

\section{Results and Discussion General recommendations}

In the case of methamphetamine intoxication, the following symptoms may occur to varying degrees:

- medical-somatic symptoms, such as sympathoadrenergic symptoms (high blood pressure, tachycardia, hyperthermia, diaphoresis, mydriasis, or agitation) and complications such as uncontrolled hypo-/hypertension, cardiac arrhythmia, circulatory problems, seizures, respiratory depression, chest pain, strokes, brain hemorrhage, and disorders of consciousness.

The level of tachycardia or hypertonus usually is a good indication of the degree of methamphetamine intoxication [5].

- mental symptoms such as expansive-aggressive states,

- Table 1 Search strategies.

\begin{tabular}{|c|c|c|c|}
\hline Database & Search words & Filter & Matches \\
\hline $\begin{array}{l}\text { Cochrane Library } \\
\text { Date: } 04.06 .2015\end{array}$ & $\begin{array}{l}\text { psychostimulant OR methamphetamine * OR "amphetamine- } \\
\text { type" OR psychoactive OR "amphetamine-related disorders" }\end{array}$ & Period 2000-2015 & $\begin{array}{l}\text { Cochrane } \\
\text { reviews: } 14\end{array}$ \\
\hline $\begin{array}{l}\text { Medline via PubMed } \\
\text { Date: } 09.06 .2015\end{array}$ & $\begin{array}{l}\text { (methamphetamine OR methylamphetamine OR “crystal meth” OR } \\
\text { “amphetamine type stimulants" OR “amphetamine-type stimulants” } \\
\text { OR “amphetamine derivate”) OR methamphetamine[MeSH Terms] } \\
\text { OR(“amphetamine-related disorders/rehabilitation”[Mesh] OR } \\
\text { “amphetamine-related disorders/therapy”[Mesh]) }\end{array}$ & $\begin{array}{l}\text { Period 2000-2015, English, German, human, } \\
\text { clinical trials, case report, systematic reviews }\end{array}$ & 1534 \\
\hline $\begin{array}{l}\text { PsycINFO2 } \\
\text { Date: } 26.06 .2015\end{array}$ & $\begin{array}{l}\text { methamphetamine in "Title" } \\
\text { treatment in "Abstract" }\end{array}$ & Period 2000-2015, English, German, human & 466 \\
\hline PSYINDEX & methamphetamine * in "text field" & Period: 2000-2015, English, German, human & 13 \\
\hline
\end{tabular}


- Table 2 Oxford Centre for Evidence-Based Medicine 2011 Levels of Evidence.

\begin{tabular}{|l|l|l|l|l|}
\hline LoE $\mathbf{1}$ & LoE $\mathbf{2}$ & LoE $\mathbf{3}$ & LoE $\mathbf{4}$ & LoE $\mathbf{5}$ \\
\hline $\begin{array}{l}\text { Systematic review of } \\
\text { randomized trials }\end{array}$ & $\begin{array}{l}\text { Randomized trial or observati- } \\
\text { onal study with dramatic effect }\end{array}$ & $\begin{array}{l}\text { Non-randomized, controlled } \\
\text { cohort/follow-up study }\end{array}$ & $\begin{array}{l}\text { Case series, case-control studies, } \\
\text { or historically controlled studies }\end{array}$ & $\begin{array}{c}\text { Mechanism-based } \\
\text { reasoning }\end{array}$ \\
\hline
\end{tabular}

- Table 3 Guideline databases searched.

\begin{tabular}{|c|c|c|c|}
\hline Database & URL & Matches & Relevant \\
\hline Association of Scientific Medical Societies in Germany (AWMF) (D) & http://www.awmf.org & 28 & 0 \\
\hline Guidelines International Network (GIN) (International) & http://www.g-i-n.net & 19 & 0 \\
\hline National Guideline Clearinghouse (NGC) (USA) & http://www.guidelines.gov & 72 & 0 \\
\hline Canadian Medical Association Guidelines Infobase (CA) & http://www.cma.ca & 18 & 0 \\
\hline National Institute for Health and Clinical Excellence (NICE) (GB) & http://www.nice.org.uk & 5 & 1 \\
\hline Evidence Search & http://www.evidence.nhs.uk/ & 33 & 1 \\
\hline Scottish Intercollegiate Guidelines Network (SIGN) (GB) & http://www.sign.ac.uk & 12 & 0 \\
\hline Institute for Clinical Systems Improvement (ICSI) (USA) & https://www.icsi.org & 39 & 0 \\
\hline World Health Organization (WHO) (International) & http://www.who.int & 8 & 1 \\
\hline American Psychiatric Association (APA) (USA) & http://www.psychiatry.org/ & 1 & 1 \\
\hline European Psychiatric Association (EPA) (European) & http://www.europsy.net/ & 16 & 0 \\
\hline European College of Neuropsychopharmacology (ECNP) (European) & http://www.ecnp.eu) & 14 & 0 \\
\hline Manual search & & 5 & 5 \\
\hline
\end{tabular}

- Table 4 Grades of Recommendation.

\begin{tabular}{|l|l|l|}
\hline Strong recommendation & Should/should not & $\Uparrow \Uparrow / \downarrow \Downarrow$ \\
\hline Recommendation & Ought to/ought not to & $\Uparrow / \Downarrow$ \\
\hline Open recommendation & $\begin{array}{l}\text { May be considered/no } \\
\text { specific recommendation }\end{array}$ & $\Leftrightarrow$ \\
\hline
\end{tabular}

agitation with poorly controllable fits of rage, stereotyped behavior, and anxious-agitated, delirious, or psychotic states with hallucinations and delusions.

- psychosocial complications such as aggressive behavior, traffic offences, and criminal offences.

Severity of intoxication symptoms depends on dose and duration of methamphetamine intake. The symptoms may persist for several hours. The risk for aggressive behavior is particularly high in the case of a psychotic disorder and/or when methamphetamine intake is coupled with drinking of alcohol [6].

During the acute intoxication, it may be difficult to take the medical history from the person affected. Therefore, information from a third party and consideration of the social environment of the patient are important for making a diagnosis. The possibility of methamphetamine intoxication should be considered in every patient presenting with diaphoresis, hyperthermia, hypertonia, tachycardia, severe agitation, or psychosis. Initially, the amount and type of substance (or substances) involved are mostly unknown. Hence, it is difficult to predict the clinical course. The management of any sympathoadrenergic syndrome including methamphetamine intoxication follows a syndrome-oriented approach. Monitoring the autonomic nervous system and psychopathological symptoms is crucial. A positive result from a qualitative urine test ("tox screening") increases the probability of methamphetamine intoxication. However, a negative test cannot rule out life-threatening methamphetamine intoxication.
A person suffering from a methamphetamine intoxication ought to be treated in a quiet, low-stimulus environment if possible (LoE $5 ; \Uparrow)[2]$.

The emphasis is on care and calming of the affected individual and on attending to or preventing secondary harm due to panic or expansive and aggressive behavior. According to clinical experience, a quiet, protective space and talking down the patient is crucial. As far as possible, the patient should be attended to by the same member of staff. Family or friends of the patient, who might help to calm him or her down, can also be involved. Doctors and nursing staff should listen to the patient and try to explain to him or her the situation and their acts in simple, short sentences. Their basic attitude should be empathic and accepting (no reproaches or confrontations!). Any potentially irritating or misleading forms of behavior such as abrupt movements or approaching the patient rapidly should be avoided. When these principles are respected, clinical experience shows that sedating medication may not be required [7].

In an emergency situation with aggressive patients, it is essential for helpers to always keep their own safety and health in mind (keep an exit route open, high level of staffing, at least a second person who can intervene or go for help). There are established and, in some cases, evaluated de-escalation management concepts for staff in health care and social services (e. g., www.prodema-online.de).

As far as possible, physical restraints (fixation) should be avoided, as they will almost always promote further escalation of agitation and aggression. Of note, physical restraints are associated with increased risk of life-threatening conditions (e. g., rhabdomyolysis, hyperthermia, etc.) and sudden death. Nevertheless, temporary use of restraint may be unavoidable in exceptional situations (e. g., aggressive attacks by the patient). In this case, a standard procedure and high staffing are needed (usually 5 people). Given the risk for the patient, attendance by a qualified professional nurse is recommended throughout restraint (1:1 care). 
> Table 5 Psychopharmacological treatment of methamphetamine intoxication.

\begin{tabular}{|l|l|}
\hline \multicolumn{2}{|l|}{ First choice: benzodiazepines } \\
\hline Substance & Typical doses and dosage intervals \\
\hline Diazepam & $10 \mathrm{mg}$ orally, if necessary repeat after $30 \mathrm{~min}$; alternatively, 2.5-5.0 mg i.v. bolus, if necessary repeat after 5-10 min \\
\hline Midazolam & $\begin{array}{l}5-10 \mathrm{mg} \text { orally (tablets or drops), if necessary repeat after 30 min; alternatively, 2.0-2.5 mg i.v. bolus or i.m., if necessary repeat } \\
\text { after } 5-10 \mathrm{~min}\end{array}$ \\
\hline Lorazepam & $1.0-2.5 \mathrm{mg}$ orally, if necessary repeat after $60 \mathrm{~min}$; alternatively, 2-4 mg i.v. bolus, repeat after 5-10 min \\
\hline Add-on treatment, if neccessary: antipsychotics \\
\hline Substance & Typical doses and dosage intervals \\
\hline Olanzapine & $10 \mathrm{mg}$ orally (orally dissolving tablets), if necessary repeat after 60 min; alternatively, 5-10 mg i.m., if necessary repeat after 120 min \\
\hline Risperidone & $2 \mathrm{mg}$ orally (orally dissolving tablets), if necessary repeat after 60 min \\
\hline $\begin{array}{l}\text { Second choice: } \\
\text { Haloperidol }\end{array}$ & $5 \mathrm{mg}$ orally (tablets or drops), if necessary repeat after $60 \mathrm{~min}$; alternatively, 5-10 mg i.m., if necessary repeat after 5-10 min \\
\hline In most cases, high cumulative doses are to be expected \\
\hline
\end{tabular}

After a methamphetamine intoxication, a psychiatric evaluation for substance-use disorders and, if appropriate, further addiction treatment should be recommended (LoE 5; $\Uparrow$ ).

Once the intoxication has abated, many patients are receptive to psychoeducation and recommendations for diagnostics and treatment. Diagnostic procedures should include a psychiatric evaluation for addiction and comorbid psychiatric disorders. If appropriate, contacts to the professional support system should be establishment in order to promote further treatment (e. g., psychiatrist, specialist outpatient addiction treatment center, counselling facility).

\section{Pharmacological interventions in acute methamphe- tamine intoxication}

No evidence is available on pharmacological interventions in acute methamphetamine intoxication. Recommendations reflect the consensus of the working group based on their clinical experience (see Acknowledgment). The systematic search for guidelines came up with consensus-based guidelines of moderate methodological quality on the emergency management of patients with psychostimulant intoxication syndrome [7]. Overall, the level of evidence of recommendations is weak.

In the case of an intoxication with several (unknown) substances, no medication ought to be given, unless sufficient monitoring of cardiovascular parameters can be provided (LoE 5; $\Uparrow$ ).

In an acute situation, it is often unclear which substance or combination of substances is involved. In this case, it is advisable to be reticent with the administration of medication if or as long as no adequate monitoring of cardiovascular parameters is provided. Possible interactions can exacerbate disorienting and respiratory depression (e.g., benzodiazepines in the case of a mixed intoxication with alcohol, liquid ecstasy, or certain natural hallucinogens [fly agaric toadstools, angel's trumpets, etc.]). Resuscitation equipment must be available, and monitoring of cardiovascular parameters (e. g., heart rate, blood pressure, blood oxygen) must be ensured for the duration of action of the medication given, especially outside emergency wards.

In the case of methamphetamine intoxication with severe agitation, aggressiveness, or psychotic symptoms requiring pharma- cological treatment, benzodiazepines should be given as first-line medication (LoE 5; $\Uparrow$ ).

Fast-acting benzodiazepines are the first choice in the case of severe agitation, threatening or manifest aggressive behavior towards the patient himself/herself or others, or psychotic symptoms. - Table 5 gives some typical doses and dosage intervals. Sedation should not be so deep that the patient becomes unconscious. In most cases, no other medication apart from benzodiazepines is needed.

In the case of methamphetamine intoxication, an additional medication with an antipsychotic may be considered if the administration of benzodiazepines is not sufficient ( $\operatorname{LoE} 5 ; \Leftrightarrow)$.

In the case of hallucinations and delusions, it may be appropriate to administer an add-on antipsychotic medication. Based on clinical experience, second-generation antipsychotics such as olanzapine are the first choice. First-generation antipsychotics, like butyrophenones (haloperidol), may be an alternative choice; however, they have a high risk for acute side effects (in particular acute dystonia). Furthermore, butyrophenones may worsen symptoms of dysphoria and anxiety [8, 9]. \ Table 5 gives some typical doses and dosage intervals.

Epileptic seizures are a frequent complication of methamphetamine intoxication. Here, too, benzodiazepines are the first choice. In contrast, antipsychotics usually lower the threshold for seizures.

Once there is no further intake of methamphetamine, the ingested methamphetamine has been excreted, and normal sleep patterns have been reestablished, psychotic symptoms from methamphetamine intoxication mostly ease within hours or 1-2 days. The need for continuation of antipsychotic medication should be reviewed continuously during the course of treatment of methamphetamine intoxication and at the latest after 3 days $[7,8]$ (

\section{Pharmacotherapy of methamphetamine-induced psychosis}

The use of an antipsychotic medication is indicated in case of psychosis following methamphetamine use and extending beyond the period of the pharmacologic action of the drug. According to ICD10 criteria, (meth)amphetamine-induced psychosis (F15.5x) evolves during intoxication or within a few days of last use and lasts for 
- Table 6 Basic guidelines for the management of an acute methamphetamine intoxication (based on [8]).

\begin{tabular}{|l}
\hline - Warning signs of life-threatening psychostimulant-induced toxic \\
syndrome \\
- chest pain \\
- increase in body temperature \\
- epileptic seizures, stroke-like symptoms \\
- hypertensive crisis (RR $>180 / 110 \mathrm{mmHg}$ ) \\
- psychotic symptoms (hallucinations, paranoid delusions) \\
- abnormal behavior (agitated, difficult to control, maniform) \\
- Monitoring of vital signs \\
- heart rate \\
- blood pressure \\
- respiratory rate \\
- body temperature \\
- blood oxygen saturation \\
- Verbal and non-verbal de-escalation \\
- speak calmly and soothingly \\
- low-stimulus environment \\
- avoid physical restraints as far as possible, as they will usually \\
cause further escalation \\
- helper's safety first (e. g., avoid or remove objects that could be \\
used as weapons, always keep an exit route open) \\
\hline - Sedative medication, if needed \\
- Encourage fluid intake and provide regular surveillance (e. g., nurse, \\
close friend)
\end{tabular}

several days to weeks. Some lighter (residual) symptoms may persist for up to 6 months.

An antipsychotic ought to be administered as first-choice medication for the treatment of methamphetamine-induced psychosis. Within 6 months, the indication ought to be reviewed. Given the more favorable side-effect profile, preference ought to be given to a second-generation antipsychotic drug (LoE 2; $\Uparrow$ ).

Olanzapine and haloperidol were equally effective in an RCT involving 58 patients with amphetamine psychosis. Haloperidol use was associated with a higher rate of acute extrapyramidal motor side effects, resulting in an increased rate of therapy discontinuations. In contrast, weight gain was more frequent on olanzapine [10]. In another RCT enrolling 80 patients with methamphetamine-induced psychosis, low doses of quetiapine and haloperidol were equally effective and accepted by the patients [11]. In another RCT, risperidone proved superior to aripiprazole in reducing positive symptoms [12]. In contrast, another RCT with 42 patients with a methamphetamine-induced psychosis showed similar efficacy of risperidone and aripiprazole. However, the acceptance of risperidone was better, and a higher number of therapy discontinuations was observed on aripiprazole [13]. Overall, given the limited evidence, no specific recommendation for a specific secondgeneration antipsychotic medication can be given for the treatment of methamphetamine-induced psychosis.

No trials have investigated the optimum duration of antipsychotic medication for methamphetamine-induced psychosis. Antipsychotic medication should be reviewed after 6 months at the latest, and if possible, it should be tapered off. If there are persisting psychotic symptoms after 6 months of methamphetamine abstinence, the diagnosis of a schizophrenic disorder must be considered.
A benzodiazepine may be considered temporarily as an add-on treatment to an antipsychotic medication of a methamphetamineinduced psychosis ( $\operatorname{LoE} 5 ; \Leftrightarrow$ ).

No evidence is available on the use of benzodiazepines in the treatment of methamphetamine-induced psychosis. According to the clinical experience of the experts, add-on benzodiazepines may be helpful in the case of ongoing psychotic symptoms if antipsychotic medication is not sufficient. Add-on benzodiazepines may attenuate the acute threat to the patient himself/herself or others (e. g., due to pronounced depressive mood swings or acute anxiety symptoms). Benzodiazepines themselves are addictive. Therefore, the dose should be as low as possible with limited treatment duration.

\section{General treatment of methamphetamine withdrawal}

The main goals of physical detoxification are alleviation of withdrawal symptoms and prevention of complications. The goals also include diagnostic evaluation, counselling, and, where appropriate, commencement of treatment of physical and psychiatric disorders. Moreover, social counselling and the introduction of the first steps towards socio-rehabilitative procedures may be appropriate. The special feature of qualified withdrawal treatment is to integrate somatic, psychiatric, psychotherapeutic, and social work [8].

According to clinical experience, the need for treatment in methamphetamine-dependent users is similar to heroin and cocaine addicts. Withdrawal symptoms include craving, exhaustion, cognitive impairments, sleep disorders, irritability, agitation, depressive-anxious moods, and sometimes even suicidal ideation. Withdrawal symptoms may be very heavy for at least 1 week and somewhat milder for at least another 2 weeks [14]. Craving lasts far longer and presents a high risk of relapse, particularly in outpatient treatment [15-17].

Given the high risk of relapse, the duration of qualified withdrawal treatment should consider the needs of the individual patient and extend beyond the abatement of acute withdrawal symptoms in order to achieve sufficient, mental, somatic, and social stability for further treatment. However, up to now, there is no clear evidence concerning which patients do better with in- or outpatient treatment.

Treatment of a methamphetamine withdrawal should be at least 3 weeks, particularly in the case of high and regular substance consumption (LoE $5 ; \Uparrow \Uparrow)[14,18]$.

\section{Pharmacotherapy of methamphetamine withdrawal}

Fifty-eight publications on pharmacotherapy of withdrawal from amphetamine-type stimulants were identified. However, only a few studies focused on methamphetamine-dependent patients. Furthermore, they had considerable methodological limitations (small sample sizes, high drop-out rates), and only a few studies addressed specifically withdrawal treatment. Hence, only findings of limited reliability are available for methamphetamine withdrawal, and many of the recommendations are extrapolations from studies with cocaine- and other amphetamine-type-stimulant-dependent patients.

Only 2 RCTs were available on the use of antidepressants for withdrawal of methamphetamine-dependent users. A study with 20 participants showed that bupropion reduced methamphetami- 
ne-induced subjective effects ("high") and cue-induced craving, but it had no effect on depressive mood or anxiety [19]. Another study $(n=31)$ failed to show any effect of mirtazapine on retention rate or withdrawal symptoms such as sleep disorders, anxiety, and depression [20-22].

There was no evidence to support the efficacy of selective serotonin reuptake inhibitors (SSRI) in alleviating methamphetamine withdrawal symptoms. In fact, there is a risk of a serotonergic syndrome and a higher rate of side effects with SSRI in methamphetamine users [23].

There were no studies on tricyclic antidepressants (TCAs) in the acute treatment of methamphetamine-dependent users [24]. However, TCAs like desipramine are effective against withdrawal symptoms in cocaine addicts [25]. As both the pharmacology and the withdrawal symptoms of methamphetamine are quite comparable to those of cocaine, TCAs might be helpful for methamphetamine withdrawal, too.

Overall, the evidence concerning antidepressants during methamphetamine withdrawal is poor, in some cases contradictory, and probably very much dependent on the random sample examined (especially consumption duration and pattern) and the treatment setting $[22,26]$.

If, in the case of methamphetamine withdrawal, the prevailing signs are depressive-anxious symptoms, exhaustion, and/or hypersomnia, bupropion or a TCA with activating properties such as desipramine may be considered ( $\operatorname{LoE} 5 ; \Leftrightarrow)$.

If insomnia and/or agitation prevail, an antidepressive medication with more sedative properties may be considered ( $\operatorname{LoE} 5 ; \Leftrightarrow)$.

These recommendations refer to symptoms during acute withdrawal. Reference is made here to the publication by Härtel-Petri et al. (this journal page 96) for the treatment of a comorbid depressive disorder.

First-generation antipsychotic medication with high potency ought not to be used to alleviate withdrawal symptoms in the acute treatment of methamphetamine patients (LOE 2; $\downarrow$ ).

There is neither a rationale nor evidence for the use of first-generation antipsychotic medication to alleviate withdrawal symptoms.

For second-generation antipsychotics, RCTs on aripiprazole are available that show no or only marginal effects compared to placebo [20, 27-29]. In 1 study, an exacerbation of methamphetamine craving was described on aripiprazole [28]. There are no studies on other antipsychotic medications for the treatment of withdrawal symptoms. According to clinical experience, olanzapine or quetiapine might be helpful in the management of agitation, tension, or insomnia during methamphetamine withdrawal.

Benzodiazepines may be considered in inpatient withdrawal treatment of methamphetamine-dependent users to attenuate an acute threat of harm to the patient himself/herself or others or to treat pronounced anxiety symptoms ( $L o E 5 ; \Leftrightarrow$ ). Given the addictive potential, benzodiazepines should be administered at the lowest possible dose and should be tapered off as soon as possible (LoE 5; $\Uparrow$ ).

No evidence is available on the use of benzodiazepines for the treatment of methamphetamine withdrawal. The general use of benzodiazepines in conjunction with uncomplicated methamphetamine withdrawal does not seem appropriate. However, add-on benzodiazepines may be helpful in the case of ongoing psychotic symptoms if antipsychotic medication is not sufficient. Add-on benzodiazepines may attenuate the acute threat to the patient himself/ herself or others (e. g., due to pronounced depressive mood swings or acute anxiety symptoms). Nevertheless, benzodiazepines should be tapered off as soon as possible.

In justified individual cases and if previous withdrawal attempts have failed, sustained-release dexamphetamine may be considered in inpatient withdrawal treatment to alleviate withdrawal symptoms in methamphetamine-dependent users ( $\operatorname{LoE} 2 ; \Leftrightarrow)$

When sustained-release dexamphetamine is used in inpatient withdrawal treatment to alleviate withdrawal symptoms, the dose should be individually titrated and then tapered off no later than the time of discharge (LoE 5 based on $[20,24,30]$; $\Uparrow \Uparrow$ ).

Sustained-release dexamphetamine should not be given to treat methamphetamine withdrawal in an outpatient setting (LoE 5; $\downarrow \downarrow)$.

A small RCT with 49 methamphetamine-dependent users investigated reduction of use after 3 months on sustained-release dexamphetamine versus placebo. At the end of the "stabilization phase" (corresponds to the withdrawal phase), the average dose was $80 \mathrm{mg} /$ day. Although there was no significant difference to placebo for the primary endpoint, a reduction in withdrawal symptoms in the stabilization phase was demonstrated as a secondary endpoint. The study had several limitations (secondary endpoint, small sample size, high drop-out rate of $53 \%$ ) $[20,24,30]$. In another small RCT, which enrolled 60 methamphetamine-dependent users, $60 \mathrm{mg} /$ day of sustained-release dexamphetamine were tolerated as well as placebo (primary endpoint: tolerance) and the drop-out rate was $13 \%$ in both treatment arms [31]. Regarding the secondary endpoints, there was no reduction in the level of use, but a reduction in withdrawal symptoms (Amphetamine Withdrawal Questionnaire) and craving (measured using a visual analogue scale). The clinical relevance of these effects seems to be limited; for instance, the difference in severity of withdrawal of around 3 points (score of 15 vs. 12) was seen for only 2 of the 8 withdrawal severity scorings. Similarly, the reduction in craving was demonstrated in only 2 out of 8 craving scorings during withdrawal. This trial, too, has several limitations (secondary endpoint, small sample size).

Due to the limited evidence, no specific recommendation can be made. Given the high drop-out rate amongst methamphetamine users during withdrawal, inpatient treatment with dexamphetamine may be justified (e. g., when patients have already dropped out from previous withdrawals). Sustainable-release dexamphetamine should be titrated individually and should be tapered off within 2 weeks and no later than at the time of discharge from the inpatient setting. Needless to say, dexamphetamine is a narcotic and has potential for abuse. Hence, the patient should not be supplied with any of this medication on discharge from inpatient treatment, nor should it be prescribed for outpatients.

For other stimulants, either no evidence was available for the acute treatment of methamphetamine-dependent users (methylphenidate), or the available studies did not show any effects or they only showed marginal benefits compared to placebo [32-36]. Hence, several small RCTs with modafinil failed to demonstrate clinically relevant improvements [32-36].

$\mathrm{N}$-acetylcysteine may be considered for alleviating methamphetamine craving during withdrawal ( $\operatorname{LoE} 2 ; \Leftrightarrow)$. 
- Table 7 Synopsis of symptom-oriented pharmacological treatment.

\begin{tabular}{|c|c|c|}
\hline Symptom & Treatment options & $\begin{array}{l}\text { Strength of } \\
\text { recommendation }\end{array}$ \\
\hline $\begin{array}{l}\text { Methamphetamine-intoxication with acute agitation or } \\
\text { pronounced fluctuation of symptoms with reactions } \\
\text { that are difficult to predict }\end{array}$ & $\begin{array}{l}\text { After exhaustion of psychotherapeutic de-escalation actions, } \\
\text { preferably benzodiazepines, as soon as an adequate monitoring of } \\
\text { cardiovascular parameters is available }\end{array}$ & $\Uparrow \Uparrow$ \\
\hline Methamphetamine-induced psychotic symptoms & $\begin{array}{l}\text { Second-generation antipsychotics } \\
\text { If necessary, concomitant benzodiazepines for a limited period of time } \\
\text { Review of indication and, if possible, tapering-off attempt after } 6 \\
\text { months at the latest }\end{array}$ & $\begin{array}{l}\Uparrow \\
\Leftrightarrow\end{array}$ \\
\hline $\begin{array}{l}\text { Pronounced craving during methamphetamine } \\
\text { withdrawal }\end{array}$ & If necessary, $\mathrm{N}$-acetylcysteine with $600-1200 \mathrm{mg} /$ day & $\Leftrightarrow$ \\
\hline $\begin{array}{l}\text { Sleep disorders and/or agitation during methampheta- } \\
\text { mine withdrawal }\end{array}$ & $\begin{array}{l}\text { Sedating antidepressants or sedating antipsychotics } \\
\text { Avoid hypnotics! }\end{array}$ & $\Leftrightarrow$ \\
\hline $\begin{array}{l}\text { Acute depressive and/or anxious symptoms with risk of } \\
\text { harm to patient or others during methamphetamine } \\
\text { withdrawal }\end{array}$ & If necessary, benzodiazepines for a limited period of time & $\Leftrightarrow$ \\
\hline $\begin{array}{l}\text { Depressive-anxious symptoms with exhaustion and/or } \\
\text { hypersomnia during methamphetamine withdrawal }\end{array}$ & Bupropion or TCAs, especially desipramine & $\Leftrightarrow$ \\
\hline $\begin{array}{l}\text { In the case of repeated failed withdrawal attempts in } \\
\text { the past }\end{array}$ & $\begin{array}{l}\text { Dexamphetamine (individual cases, only in an inpatient setting), } \\
\text { wash-out of the dose after } 2 \text { weeks at the latest }\end{array}$ & $\begin{array}{l}\Leftrightarrow \\
\Leftrightarrow\end{array}$ \\
\hline
\end{tabular}

A small $(n=32)$, but otherwise methodologically sound, randomized, placebo-controlled study with a cross-over design showed a favorable effect of $\mathrm{N}$-acetylcysteine on craving in the acute treatment phase coupled with very good tolerability. The dose was $600 \mathrm{mg}$ in the first week and $1200 \mathrm{mg}$ in the second to fourth week followed by wash-out over 3 days [37].

Another randomized, placebo-controlled study with 18 participants demonstrated an attenuation of some subjectively positive methamphetamine-induced effects (agitation, drive, energizing effects) by the calcium antagonist israpidine. However, israpidine was not well tolerated during methamphetamine withdrawal [38]. Another small, placebo-controlled RCT $(n=30)$ revealed a weakening of cue-induced craving and reduction of a few subjectively pleasant effects of methamphetamine by naltrexone. However, in addition to the small number of participants, this study had further methodological limitations [39]. Other RCTs showed that topiramate, ondansetron, and a combination of 2 pharmacological agents (flumazenil and gabapentin or $\mathrm{N}$-acetylcysteine and naltrexone) were not superior to placebo [40-43].

In a small placebo-controlled RCT $(n=26)$, varenicline enhanced the information processing speed of patients during methamphetamine withdrawal. Moreover, varenicline attenuated the subjectively positive methamphetamine-induced effects. Apart from this, no positive effects on other symptoms of methamphetamine withdrawal or on craving were observed $[44,45]$. Given the considerable methodological flaws (small sample size, not double-blinded, conflicts of interest), the validity of this study is very limited. Two other small placebo-controlled RCTs failed to demonstrate any improvement of cognitive functions on rivastigmine. However, cognitive impairment was not seen in patients included $[46,47]$.

Based on the available evidence, $\mathrm{N}$-acetylcysteine may be considered for the treatment of methamphetamine craving during withdrawal treatment. This substance is usually well tolerated. There is also preliminary evidence that $\mathrm{N}$-acetylcysteine might have a favorable impact on craving and the risk of relapse in other sub- stance-use disorders [48-51]. The effect of $\mathrm{N}$-acetylcysteine is thought to be linked to a modulation of glutamatergic transmission; however, the exact mechanism of action has still to be elucidated [52].

\section{Synopsis: Symptom-oriented approach}

- Table 7 gives a synopsis of the recommendations for the pharmacological treatment of acute complications of methamphetamine use. The recommendations are grouped according to the target symptoms (symptom-oriented approach).

Taken together, the available evidence for the acute pharmacological treatment of methamphetamine-related disorders is limited. The recommendations are based mainly on clinical expert consensus. Benzodiazepines are first-choice medication for methamphetamine-induced intoxication syndromes, particularly if they present with acute agitation. There is no evidence-based medication for the treatment of methamphetamine-related withdrawal symptoms and craving. When treating methamphetamine-induced psychosis, second-generation antipsychotic drugs ought to be favored, given the more favorable side-effect profile. The indication for continuation of antipsychotic medication must be reviewed regularly. In most cases, the antipsychotic should be tapered off within 6 months. Overall, further research is warranted.

The complete guidelines (in German) can be downloaded at www.crystal-meth.aezq.de.

The Working Group (Co-Authors) of the S3 Guidelines

- Wolf-Dietrich Braunwarth, Klinikum Nürnberg

- Roland Härtel-Petri, Psychotherapeutische Praxis, Bayreuth

- Heribert Fleischmann, Bezirksklinikum Wöllershof

- Euphrosyne Gouzoulis-Mayfrank, LVR-Klinik Köln

- Willem Hamdorf, AHG Klinik Mecklenburg

- Ursula Havemann-Reinecke, Universitätsklinik Göttingen

- Peter Jeschke, Neurologische Gemeinschaftspraxis, Halle

- Josef Mischo, Kreiskrankenhaus St. Ingbert 
- Bernd Mühlbauer, Institut für Klinische Pharmakologie am Klinikum Bremen Mitte

- Stephan Mühlig, Technische Universität Chemnitz

- Timo Harfst, Bundespsychotherapeutenkammer

- Ingo Schäfer, Sascha Milin, Universitätsklinikum HamburgEppendorf/Zentrum für interdisziplinäre Suchtforschung der Universität Hamburg

- Norbert Scherbaum, LVR-Klinikum Essen

- Katharina Schoett, Ökumenisches Hainich Klinikum

- Frank Schulte-Derne, Landschaftsverband Westfalen-Lippe (LWL)

- Frank Vilsmeier, Psychiatrisches Krankenhaus Rickling

- Winfried Looser, LVR-Klinik Düren

- Norbert Wittmann, Benjamin Löhner, Mudra Drogenberatung

- Willem Hamdorf, AHG Klinik Mecklenburg

- Ursula Havemann-Reinecke, Universitätsklinik Göttingen

- Norbert Wodarz, Klinik und Poliklinik für Psychiatrie und Psychotherapie der Universität am Bezirksklinikum Regensburg

\section{References}

[1] Xie Z, Miller GM. A receptor mechanism for methamphetamine action in dopamine transporter regulation in brain. J Pharmacol Exp Ther 2009; 330: 316-325

[2] Rothman RB, Baumann MH, Dersch CM et al. Amphetamine-type central nervous system stimulants release norepinephrine more potently than they release dopamine and serotonin. Synapse 2001; 39: 32-41

[3] Schep L], Slaughter R], Beasley DM. The clinical toxicology of metamfetamine. Clin Toxicol (Phila) 2010; 48: 675-694

[4] Oxford Centre for Evidence-Based Medicine (OCEBM), OCEBM Levels of Evidence Working Group. The Oxford 2011 Levels of Evidence; 2011. Available at http://www.cebm.net/wp-content/uploads/2014/06/ CEBM-Levels-of-Evidence-2.1.pdf

[5] Hart CL, Gunderson EW, Perez A et al. Acute physiological and behavioral effects of intranasal methamphetamine in humans. Neuropsychopharmacology 2008; 33: 1847-1855

[6] McKetin R, Lubman DI, Najman JM et al. Does methamphetamine use increase violent behaviour? Evidence from a prospective longitudinal study. Addiction 2014; 109: 798-806

[7] Guidelines Development Working Party; Jenner J, Spain D et al. Management of Patients with Psychostimulant Toxicity: Guidelines for Emergency Departments. Canberra: Australian Government Department of Health and Ageing; 2006

[8] Turning Point Alcohol and Drug Centre; Lee N, Johns L et al No 14: Methamphetamine dependence and treatment. Fitzroy, Victoria: Turning Point Alcohol and Drug Centre; 2007

[9] Drug \& Alcohol Services South Australia (DASSA); Mclver C, McGregor $C$ et al. Guidelines for the medical management of patients with methamphetamine-induced psychosis. Morphett Vale: DASSA Southern Service; 2006

[10] Leelahanaj T, Kongsakon R, Netrakom P. A 4-week, double-blind comparison of olanzapine with haloperidol in the treatment of amphetamine psychosis. J Med Assoc Thai 2005; 88: S43-S52

[11] Verachai V, Rukngan W, Chawanakrasaesin K et al. Treatment of methamphetamine-induced psychosis: a double-blind randomized controlled trial comparing haloperidol and quetiapine. Psychopharmacology (Berl) 2014; 231: 3099-3108

[12] Farnia V, Shakeri J, Tatari F et al. Randomized controlled trial of aripiprazole versus risperidone for the treatment of amphetamineinduced psychosis. Am J Drug Alcohol Abuse 2014; 40: 10-15
[13] Wang G, Zhang Y, Zhang S et al. Aripiprazole and risperidone for treatment of methamphetamine - associated psychosis in Chinese patients. J Subst Abuse Treat 2016; 62: 84-88

[14] McGregor C, Srisurapanont M, Jittiwutikarn J et al. The nature, time course and severity of methamphetamine withdrawal. Addiction 2005; 100: $1320-1329$

[15] Zorick T, Nestor L, Miotto K et al. Withdrawal symptoms in abstinent methamphetamine-dependent subjects. Addiction 2010; 105: 1809-1818

[16] Galloway GP, Singleton EG. How long does craving predict use of methamphetamine? Assessment of use one to seven weeks after the assessment of craving: craving and ongoing methamphetamine use. Subst Abuse 2009; 1: 63-79

[17] Hartz DT, Frederick-Osborne SL, Galloway GP. Craving predicts use during treatment for methamphetamine dependence: a prospective, repeated-measures, within-subject analysis. Drug Alcohol Depend 2001; 63: 269-276

[18] Sauter D, Abderhalden C, Needham I et al. Lehrbuch psychiatrische Pflege. $3^{\text {rd }}$ edition. Bern: Huber; 2011

[19] Newton TF, Roache JD, De La Garza R et al. Bupropion reduces methamphetamine-induced subjective effects and cue-induced craving. Neuropsychopharmacology 2006; 31: 1537-1544

[20] Brackins T, Brahm NC, Kissack JC. Treatments for methamphetamine abuse: a literature review for the clinician. J Pharm Pract 2011; 24 541-550

[21] Cruickshank CC, Montebello ME, Dyer KR et al. A placebo-controlled trial of mirtazapine for the management of methamphetamine withdrawal. Drug Alcohol Rev 2008; 27: 326-333

[22] Hellem TL, Lundberg KJ, Renshaw PF. A review of treatment options for co-occurring methamphetamine use disorders and depression. J Addict Nurs 2015; 26: 14-23

[23] Shoptaw S, Huber A, Peck J et al. Randomized, placebo-controlled trial of sertraline and contingency management for the treatment of methamphetamine dependence. Drug Alcohol Depend 2006; 85: $12-18$

[24] Perez-Mana C, Castells X, Torrens M et al. Efficacy of psychostimulant drugs for amphetamine abuse or dependence. Cochrane Database Syst Rev 2013; 9: CD009695

[25] Pani PP, Trogu E, Vecchi S et al. Antidepressants for cocaine dependence and problematic cocaine use. Cochrane Database Syst Rev 2011; CD002950

[26] Rajasingham R, Mimiaga M], White JM et al. A systematic review of behavioral and treatment outcome studies among HIV-infected men who have sex with men who abuse crystal methamphetamine. AIDS Patient Care STDS 2012; 26: 36-52

[27] Coffin PO, Santos GM, Das M et al. Aripiprazole for the treatment of methamphetamine dependence: a randomized, double-blind, placebo-controlled trial. Addiction 2013; 108: 751-761

[28] Kishi T, Matsuda Y, Iwata $\mathrm{N}$ et al. Antipsychotics for cocaine or psychostimulant dependence: systematic review and meta-analysis of randomized, placebo-controlled trials. J Clin Psychiatry 2013; 74: e1169-e1180

[29] Newton TF, Reid MS, De La Garza R et al. Evaluation of subjective effects of aripiprazole and methamphetamine in methamphetaminedependent volunteers. Int J Neuropsychopharmacol 2008; 11 : 1037-1045

[30] Longo M, Wickes W, Smout M et al. Randomized controlled trial of dexamphetamine maintenance for the treatment of methamphetamine dependence. Addiction 2010; 105: 146-154

[31] Galloway GP, Buscemi R, Coyle JR et al. A randomized, placebo-controlled trial of sustained-release dextroamphetamine for treatment of methamphetamine addiction. Clin Pharmacol Ther 2011; 89: 276-282 
[32] Lee N, Pennay A, Hester R et al. A pilot randomised controlled trial of modafinil during acute methamphetamine withdrawal: feasibility, tolerability and clinical outcomes. Drug Alcohol Rev 2013; 32: 88-95

[33] Mahoney J], Jackson B], Kalechstein AD et al. Acute modafinil exposure reduces daytime sleepiness in abstinent methamphetamine-dependent volunteers. Int J Neuropsychopharmacol 2012; 15: 1241-1249

[34] Dean AC, Sevak RJ, Monterosso JR et al. Acute modafinil effects on attention and inhibitory control in methamphetamine-dependent humans. J Stud Alcohol Drugs 2011; 72: 943-953

[35] Ghahremani DG, Tabibnia G, Monterosso J et al. Effect of modafinil on learning and task-related brain activity in methamphetamine-dependent and healthy individuals. Neuropsychopharmacology 2011; 36: 950-959

[36] Hester R, Lee N, Pennay A et al. The effects of modafinil treatment on neuropsychological and attentional bias performance during 7-day inpatient withdrawal from methamphetamine dependence. Exp Clin Psychopharmacol 2010; 18: 489-497

[37] Mousavi SG, Sharbafchi MR, Salehi M et al. The efficacy of N-acetylcysteine in the treatment of methamphetamine dependence: a double-blind controlled, crossover study. Arch Iran Med 2015; 18: 28-33

[38] Johnson BA, Roache JD, Ait-Daoud $N$ et al. Effects of isradipine on methamphetamine-induced changes in attentional and perceptualmotor skills of cognition. Psychopharmacology 2005; 178: 296-302

[39] Ray LA, Bujarski S, Courtney KE et al. The Effects of Naltrexone on Subjective Response to Methamphetamine in a Clinical Sample: a Double-Blind, Placebo-Controlled Laboratory Study. Neuropsychopharmacology 2015; 40: 2347-2356

[40] Rezaei F, Ghaderi E, Mardani R et al. Topiramate for the management of methamphetamine dependence: a pilot randomized, double-blind, placebo-controlled trial. Fundam Clin Pharmacol 2016; 30: 282-289

[41] Johnson BA, Ait-Daoud N, Elkashef AM et al. A preliminary randomized, double-blind, placebo-controlled study of the safety and efficacy of ondansetron in the treatment of methamphetamine dependence. Int J Neuropsychopharmacol 2008; 11: 1-14

[42] Urschel HC 3rd, Hanselka LL, Baron M. A controlled trial of flumazenil and gabapentin for initial treatment of methylamphetamine dependence. J Psychopharmacol 2011; 25: 254-262
[43] Grant JE, Odlaug BL, Kim SW. A double-blind, placebo-controlled study of $\mathrm{N}$-acetyl cysteine plus naltrexone for methamphetamine dependence. Eur Neuropsychopharmacol 2010; 20: 823-828

[44] Kalechstein AD, Mahoney JJ 3rd, Verrico CD et al. Short-term, low-dose varenicline administration enhances information processing speed in methamphetamine-dependent users. Neuropharmacology 2014; 85: 493-498

[45] Verrico CD, Mahoney JJ 3rd, Thompson-Lake DG et al. Safety and efficacy of varenicline to reduce positive subjective effects produced by methamphetamine in methamphetamine-dependent volunteers. Int J Neuropsychopharmacol 2014; 17: 223-233

[46] Kalechstein AD, Yoon JH, Croft DE et al. Low dose, short-term rivastigmine administration does not affect neurocognition in methamphetamine dependent individuals. Pharmacol Biochem Behav 2011; 99: 423-427

[47] De La Garza R, Mahoney J] 3rd, Culbertson C et al. The acetylcholinesterase inhibitor rivastigmine does not alter total choices for methamphetamine, but may reduce positive subjective effects, in a laboratory model of intravenous self-administration in human volunteers. Pharmacol Biochem Behav 2008; 89: 200-208

[48] LaRowe SD, Kalivas PW, Nicholas JS et al. A double-blind placebocontrolled trial of $\mathrm{N}$-acetylcysteine in the treatment of cocaine dependence. Am J Addict 2013; 22: 443-452

[49] Lin SK. Pharmacological means of reducing human drug dependence: a selective and narrative review of the clinical literature. $\mathrm{Br} J$ Clin Pharmacol 2014; 77: 242-252

[50] Balter RE, Cooper ZD, Haney M. Novel Pharmacologic Approaches to Treating Cannabis Use Disorder. Curr Addict Rep 2014; 1: 137-143

[51] Marshall K, Gowing L, Ali R et al. Pharmacotherapies for cannabis dependence. Cochrane Database Syst Rev 2014; CD008940

[52] Uys JD, LaLumiere RT. Glutamate: the new frontier in pharmacotherapy for cocaine addiction. CNS Neurol Disord Drug Targets 2008; 7 : 482-491 